Contract No. and Disclaimer:

This manuscript has been authored by Savannah River Nuclear Solutions, LLC under Contract No. DE-AC09-08SR22470 with the U.S. Department of Energy. The United States Government retains and the publisher, by accepting this article for publication, acknowledges that the United States Government retains a non-exclusive, paid-up, irrevocable, worldwide license to publish or reproduce the published form of this work, or allow others to do so, for United States Government purposes. 
SRNL-STI-2010-00140

\title{
Solubility of Uranium and Plutonium in Alkaline Savannah River Site High Level Waste Solutions
}

\author{
William D. King, Tommy B. Edwards, David T. Hobbs, and William R. Wilmarth \\ Savannah River National Laboratory, Aiken, SC 29803 \\ *manuscript for publication in Separation Science and Technology
}

\begin{abstract}
Five actual Savannah River Site tank waste samples and three chemically-modified samples were tested to determine solubility limits for uranium and plutonium over a one year time period. Observed final uranium concentrations ranged from $7 \mathrm{mg} \mathrm{U} / \mathrm{L}$ to $4.5 \mathrm{~g}$ $\mathrm{U} / \mathrm{L}$. Final plutonium concentrations ranged from $4 \mu \mathrm{g} \mathrm{Pu} / \mathrm{L}$ to $12 \mathrm{mg} \mathrm{Pu} / \mathrm{L}$. Actinide carbonate complexation is believed to result in the dramatic solubility increases observed for one sample over long time periods. Clarkeite, $\mathrm{NaUO}_{2}(\mathrm{O}) \mathrm{OH} \cdot \mathrm{H}_{2} \mathrm{O}$, was found to be the dominant uranium solid phase in equilibrium with the waste supernate in most cases.
\end{abstract}

\section{BACKGROUND AND INTRODUCTION}

The solubilities and fates of actinide elements released into groundwater as a result of inadvertent release from nuclear repositories has been an area of intensive study. ${ }^{[1-2]}$ Under environmental conditions the mobility of these elements is largely determined by the groundwater $\mathrm{pH}$, redox potential, and carbonate concentration and the solubilities of 
various mineral phases. Relatively little study has focused on actinide chemistry under the highly alkaline conditions found in nuclear waste storage tanks, although the chemistry has received greater attention in recent years. ${ }^{[3-10]}$

Millions of gallons of radioactive waste produced as a legacy by-product of nuclear weapons production are stored primarily at two US Department of Energy sites in Richland, WA (Hanford Site) and Aiken, SC (Savannah River Site). Large volumes of highly acidic radioactive waste solutions were generated beginning in the 1940's from the processing of irradiated nuclear fuel materials. Adjustment of the acidic waste solutions with $\mathrm{NaOH}$ was needed to generate a waste product which was compatible with carbon steel storage tanks. The addition of $\mathrm{NaOH}$ resulted in the precipitation of base-insoluble oxides and hydroxides of various metals (major components: Fe and Al) to form an insoluble sludge waste with sufficient neutron poisons to minimize actinide criticality concerns. Base-soluble species including primarily sodium salts of hydroxide, nitrate, and nitrite remained in solution (frequently referred to as supernate) along with trace amounts of certain soluble radioactive species such as cesium and technetium.

Due to limited tank farm capacity, waste dewatering by evaporation is frequently necessary which results in the saturation of the solution in certain sodium salts (primarily nitrate and nitrite) and the subsequent crystallization of "salt-cake" solids after cooling of the solution in post-evaporation receipt tanks. The end result of this processing is a radioactive waste slurry within the tanks containing three compositionally unique phases including sludge solids, salt-cake solids, and an alkaline, high-sodium supernatant liquid. 
Knowledge of the solubilities of uranium and plutonium in waste solutions at the Savannah River Site (SRS) is needed to avoid the inadvertent precipitation and accumulation of fissile materials in process vessels and transfer pipes. Actinide elements are primarily partitioned into the solid sludge phase due to their limited solubility under alkaline conditions, but are distributed to some degree among all three phases. Any process that could lead to the separation of uranium and plutonium from the neutron poisons could potentially impact criticality safety assumptions and calculations and tank farm management practices.

Interest in this issue at SRS was in fact promoted by the observation of aluminosilicate solids in evaporator bottoms containing unexpectedly high levels of actinides, particularly uranium. Subsequent studies at SRS focused on potential mechanisms for actinide separation including sorption or co-precipitation with aluminosilicates ${ }^{[3]}$ and simple precipitation resulting, for instance, from the mixing or evaporation of waste processing solutions. Part of these studies involved the determination of actinide solubilities in various simulated SRS process solutions of prototypical chemical composition. ${ }^{[4-5]}$ Studies by other groups have focused on the determination of actinide solubilites in simulated Hanford waste solutions ${ }^{[6]}$ and on determining actinide speciation and solubility in other highly alkaline solutions ${ }^{[7-10]}$.

Very little data has been reported on actinide solubilities in actual tank waste solutions. We recently reported the results of uranium and plutonium solubility studies from one 
SRS waste tank sample where uranium super-saturation was confirmed, an issue which complicates the management of these solutions to avoid unexpected actinide deposition. $^{[3]}$ Herein we report solubility results for four additional samples retrieved from SRS waste storage tanks with highly variable composition and process histories. The results provide insight into the factors impacting actinide solubility in complex tank waste supernate solutions and provide data for comparison to models developed using simulated waste supernates.

Based primarily on studies in acidic to mildly basic $(\mathrm{pH}<12)$ solutions, the aqueous chemistry of the actinides is fairly well understood. ${ }^{[2,12]}$ The chemistry is quite complicated due to the existence of multiple stable oxidation states, hydrolysis reactions, complex formation, the formation of polymeric species of colloidal dimensions, and slow transfer kinetics between species. In many cases, multiple oxidation states and species can coexist. At high $\mathrm{pH}$ the chemistry is dominated by relatively insoluble metal oxides and hydroxides.

The SRS process and tank farm samples studied varied from low ionic strength solutions $\left(0.5 \mathrm{M} \mathrm{Na}^{+}\right)$near $\mathrm{pH} 13$ to concentrated sodium salt solutions $\left(12 \mathrm{M} \mathrm{Na}^{+}\right)$which were highly alkaline $\left(9 \mathrm{M} \mathrm{OH}^{-}\right)$. Typical SRS supernate contains 5-6 $\mathrm{M} \mathrm{Na}^{+}$and 1-4 $\mathrm{M} \mathrm{OH}^{-}$as well as numerous other anions that may form complexes with actinides and impact the solubility. Besides hydroxide, the major soluble components in the supernate include sodium salts of nitrate, nitrite, aluminate, carbonate and sulfate. Minor components include chloride, fluoride, oxalate, and phosphate salts. Of these species, carbonate, 
fluoride, sulfate, phosphate, and oxalate are known to form strong complexes with the actinides. Some evidence also exists for the formation of plutonium aluminate complexes, and high levels of nitrite have been shown to decrease plutonium solubility by impacting the solution redox potential. ${ }^{[6]}$ Carbonate complexation is particularly known to influence actinide solubilites, in some cases by orders of magnitude. ${ }^{[2]}$ Carbonate solutions have been successfully used to leach uranium from contaminated soils $^{[13]}$ and the carbonate concentration of seawater is believed to result in greater than expected uranium solubility ${ }^{[12]}$.

In strongly basic solutions the ability of carbonate or any other anion to impact actinide solubility is determined by the relative amounts of the anion and hydroxide. Furthermore, although actinide complexes with these anions may be the thermodynamically favored species, the time required to reach equilibrium may be long, due to the rapid formation of oxide and hydroxide phases which are sometimes polymeric in nature and can be slow to dissolve. We have developed statistical models to predict uranium and plutonium solubility in these complicated solutions based on measured solubility data and selected compositional parameters using simulated waste supernates. ${ }^{[4-}$

5] Plutonium predictions include the most recent model version incorporating results published by Rudisill. ${ }^{[5]}$

As is frequently the case under environmental conditions, the chemistry of the actinides in alkaline waste slurries may be largely determined by oxide, hydroxide, carbonate and mixed hydroxy-carbonate complexes and phases. Under tank waste conditions uranium 
is expected to exist as the hexavalent uranyl ion, $\mathrm{UO}_{2}{ }^{2+}$, while plutonium is primarily in the tetravalent state, $\mathrm{Pu}(\mathrm{IV})$. The dominant uranium solid phases under alkaline conditions are expected to be sodium diuranate $\left(\mathrm{Na}_{2} \mathrm{U}_{2} \mathrm{O}_{7}\right)$ or possibly Clarkeite $\left(\mathrm{NaUO}_{2}(\mathrm{O}) \mathrm{OH}\right)$, as predicted by Giammar ${ }^{[14]}$. Dominant plutonium solid phases almost certainly include the amorphous hydroxide, $\mathrm{Pu}(\mathrm{OH})_{4}$, or the hydrous oxide, $\mathrm{PuO}_{2} \cdot x \mathrm{H}_{2} \mathrm{O}{ }^{[15]}$

EXAFS studies have shown that the uranyl ion exists in highly alkaline solutions $(\geq 3 \mathrm{M}$ $\left.\mathrm{OH}^{-}\right)$as $\mathrm{UO}_{2}(\mathrm{OH})_{4}{ }^{2-}$ and $\mathrm{UO}_{2}(\mathrm{OH})_{5}{ }^{3-}$ in the absence of significant carbonate. ${ }^{[8-9]}$ Plutonium speciation in alkaline solution is believed to include the pentavalent plutonyl complex, $\mathrm{PuO}_{2}{ }^{+}$. However, $\mathrm{Pu}(\mathrm{V})$ has been shown to disproportionate to $\mathrm{Pu}(\mathrm{IV})$ and $\mathrm{Pu}$ (VI) at 4 and $6 \mathrm{M} \mathrm{OH}^{-}$while being stable in $8 \mathrm{M} \mathrm{OH}^{-[10-11]}$ Therefore all three plutonium oxidation states may be present to varying degrees depending upon the conditions (particularly the hydroxide and carbonate content and the solution redox potential). The tetrahydroxy species, $\mathrm{PuO}_{2}(\mathrm{OH})_{4}{ }^{3-}$, has been proposed as a contributing species under alkaline conditions. ${ }^{[6]}$

In the presence of carbonate, various possible carbonate, hydroxy-carbonate, and oxycarbonate actinide complexes are possible including trimeric species containing three metal atoms (particularly the case for uranium). Evidence exists for the formation of the di- and tri-carbonate uranyl complexes, $\mathrm{UO}_{2}\left(\mathrm{CO}_{3}\right)_{2}{ }^{2-}$ and $\mathrm{UO}_{2}\left(\mathrm{CO}_{3}\right)_{3}{ }^{4-}$, respectively, as well as the trimeric carbonate complex $\left(\mathrm{UO}_{2}\right)_{3}\left(\mathrm{CO}_{3}\right)_{6}{ }^{6-} \cdot[16-18]$ Carbonate complexes may also form for the three plutonium oxidation states. These uranium and plutonium 
hydroxy and carbonate complexes are expected to be dominant species existing in alkaline tank waste with other actinide complexes contributing to some degree depending upon the concentrations of the complexing anions. The solubilities of uranium and plutonium are expected to increase with hydroxide content ${ }^{[4,6]}$ with the potential for dramatic solubility increases as the degree of carbonate complexation increases. ${ }^{[1]}$

The SRS tank supernate samples selected for testing included process recycle streams, evaporator feed and drop tanks, dormant tanks containing cladding waste, and dissolved tank solids (salt-cake). Testing involved approaching saturation from over- and undersaturated states by the addition of small volumes of acidic spike solutions or preformed solids, respectively. Uranium and plutonium solubility tests were conducted simultaneously with each sample at $25{ }^{\circ} \mathrm{C}$ using hexavalent uranium and tetravalent plutonium. Long time periods (approaching one year) were required to approach equilibrium for both actinides in most samples. Additional solubility tests were conducted on chemically-modified supernate samples to gain insight as to the chemical species leading to the extremely high solubilities observed with one sample. Results are compared to predictions generated with statistically-based models developed at the Savannah River National Laboratory (SRNL).

\section{EXPERIMENTAL}

Four of the five SRS tank samples were received for testing as liquid supernate solutions. The fifth sample was received as solid saltcake, which was subsequently dissolved in water. Prior to analysis and testing each sample was filtered through a $0.45-\mu$ m nylon 
cup filter and the density of the filtrate was measured in duplicate using $10-\mathrm{mL}$ liquid sub-samples. Anion chromatography, hydroxide, and carbonate analyses were conducted on sub-samples diluted 1:15 by mass with water while all other analyses were conducted on sub-samples diluted approximately 1:15 by mass with $3 \mathrm{M}$ nitric acid. Several days were allowed for sample stabilization after dilution in nitric acid prior to analysis based on previous data which indicated that this might be necessary for accurate plutonium analysis.

All tests were conducted using approximately $25 \mathrm{~mL}$ of solution in $60-\mathrm{mL}$ Teflon bottles. The uranyl (VI) nitrate $\left(\mathrm{UO}_{2}\left(\mathrm{NO}_{3}\right)_{2}\right)$ spike solution used for testing contained $326 \mathrm{~g} \mathrm{U} / \mathrm{L}$ in $0.05 \mathrm{M} \mathrm{HNO}_{3}$. The plutonium (IV) spike solution used for testing contained $6.3 \mathrm{~g}$ $\mathrm{Pu} / \mathrm{L}$ in $0.01 \mathrm{M} \mathrm{HNO}_{3}$. Solubility tests were conducted by over-saturation and undersaturation methods involving the addition of small volumes of acidic spike solutions or preformed solids, respectively, to separate test samples. Sample agitation and temperature control were accomplished by placing the samples in a temperaturecontrolled orbital shaker oven (Innova Model 4230). Samples were continually agitated using a horizontally-oriented orbital rotation and the bottles were positioned with the long axis vertical. The shaker rotation rate was maintained at approximately 250 RPM throughout the entire test duration, except during sampling events when agitation was briefly stopped. The oven temperature was monitored using a calibrated thermocouple with digital readout. Temperature variation was less than $\pm 3{ }^{\circ} \mathrm{C}$ throughout the duration of testing. 
Sampling was conducted at irregular intervals as needed to track the solubilities of uranium and plutonium in solution. Sampling volume and frequency were minimized to avoid sample consumption during testing. Each sample submitted for uranium or plutonium analysis was previously filtered at temperature through a $0.45-\mu \mathrm{m}$ nylon syringe filter attached to a 5-mL disposable syringe. The typical sample mass after filtration was $0.5 \mathrm{~g}$. The samples were filtered directly into approximately $7.5 \mathrm{~g}$ of $3 \mathrm{M}$ nitric acid to avoid post-filtration precipitation.

Since test plans involved the simultaneous determination of uranium and plutonium solubilities in the same solutions, preliminary scoping tests were conducted using an over-saturation approach to determine whether co-precipitation or the order of addition impacted the solubility. Tests were conducted with Sample \#1 supernate involving the following spike sequences: $\mathrm{U}$ then $\mathrm{Pu}, \mathrm{Pu}$ then $\mathrm{U}, \mathrm{U}$ then Pu blank, $\mathrm{U}$ blank then $\mathrm{Pu}$, and U blank then Pu blank. The blank solution used for these evaluations was $0.05 \mathrm{M}$ nitric acid, which is the same concentration as the more acidic of the two spike solutions. These tests were also intended to evaluate whether the addition of small volumes of acid spike solutions to the alkaline waste samples promoted precipitation or significantly altered the samples or results. Typical spike volumes were $\leq 0.4 \mathrm{~mL}$ for all samples tested which was $\leq 2 \%$ by volume of the original sample and resulted in negligibly small sample neutralization. Sample \#1 was used for these evaluations because it contained the lowest hydroxide concentration and would therefore be expected to be impacted the greatest by the acid spike solution. 
Results of the scoping studies confirmed that: 1) the order of spike addition did not matter, 2) addition of acid blank solution alone did not change the measured $\mathrm{U}$ or $\mathrm{Pu}$ concentrations or promote visible precipitation, 3) the formation of uranium or plutonium solids for this particular sample resulted in the removal of uranium from solution down to the solubility limit, and 4) co-precipitation did not affect the results. As will be discussed later, observation \#3 was associated with the fact that this particular sample was supersaturated in uranium. Otherwise these results indicated that the test methodology involving simultaneous determination of $\mathrm{U}$ and $\mathrm{Pu}$ solubilities was valid.

All subsequent over-saturation tests were conducted in duplicate using an initial uranium spike followed by a plutonium spike approximately five minutes later. Sample spiking was conducted in all cases with continuous sample agitation initially using a stir bar. Solids were immediately observed upon addition of the uranyl spike but were not visually observed after the plutonium spike (even during Pu-only spikes) because the total mass of precipitated solids was too small. For two test solutions (\#2 and \#3), sub-samples were collected within a few minutes and within an hour after spiking to confirm that saturation was approached from a super-saturated state. Solids were generated for under-saturated tests for all solutions by spiking samples of supernate as described above and then isolating the solids formed after one week. The solids were isolated on a $0.45-\mu$ m nylon filter cup and quickly washed with one additional portion of supernate. The damp solids were then isolated and transferred directly into a third portion of fresh supernate of known mass to initiate the under-saturated test. From this point on all samples (both 
over- and under-saturated) were maintained in the oven and sampled at approximately the same times for comparison.

All chemical analyses were conducted in the SRNL Analytical Services laboratories using standard techniques and following all applicable laboratory quality assurance protocols. Analytical results for the five original tank samples are provided in Table 1. Note that the numbers used for sample identification were arbitrarily assigned and do not correspond to specific tank numbers. Tank sample histories and descriptions are provided in Table 2 .

Three portions of chemically-modified Sample \#1 solution were also used for solubility testing. Chemical modifications were conducted to evaluate and compare the effects of high levels of nitrate, sulfate, and carbonate in the presence of low hydroxide. Sodium carbonate, sodium nitrate, and sodium sulfate were added to three separate portions of Sample \#1 to increase the total sodium concentration to near $2 \mathrm{M}$. The final measured carbonate and sulfate concentrations in Samples 1-C and 1-S were 0.75 M, while the final nitrate concentration in Sample 1-N was 1.6 M. These additions resulted in final added anion:hydroxide ratios of 4.5 for the 1-C and 1-S samples and 9.5 for the 1-N sample.

Selected analysis results for the chemically-modified samples are provided in Table 3. Carbonate and hydroxide analyses were conducted by titration. Due to radiological handling limitations on the amount of sample that could be removed from the shielded cells environment, higher detection limits were observed for the carbonate analyses of 
Samples \#2 and \#5. Ion chromatography was used to determine the concentrations of the other anions (nitrate, nitrite, fluoride, chloride, phosphate, sulfate, formate, and oxalate). The concentrations of soluble metal ions such as aluminum were determined by inductively coupled plasma emission spectroscopy (ICP-ES). Uranium concentrations were determined by inductively couple plasma mass spectroscopy (ICP-MS). Plutonium concentrations were determined by alpha counting with pulse-height analysis to assure the rejection of other alpha-emitting radioactivity. The elemental composition and crystalline phases present in solid samples isolated at the conclusion of the solubility testing were determined by Energy Dispersive X-ray Spectroscopy (EDS) and X-ray Diffraction (XRD) techniques.

\section{RESULTS AND DISCUSSION}

Uranium and plutonium solubility testing was conducted over a one year time period with five actual SRS radioactive waste process solutions of various ages, histories and chemical compositions and three additional chemically-modified supernate samples. Initial $\mathrm{U}$ and $\mathrm{Pu}$ concentrations in the samples, $\mathrm{U}$ and $\mathrm{Pu}$ spike levels for each sample, and predicted and measured solubilities for each original sample at various test durations are provided in Table 4. Plots of the uranium and plutonium solubility data for the five original supernate samples are provided in Figures 1 and 2, respectively.

Solubilities determined by over-saturation and under-saturation methods generally converged with time. Therefore only solubility data provided by over-saturation are provided. Spike levels were typically considerably higher than the measured solubilities 
except for Sample \#3, where the final measured concentrations approached the spike levels (discussed further below). Uranium and plutonium solubilities were determined simultaneously in the same supernate samples. This is similar to the conditions observed in the waste tanks since both solids co-exist under these conditions, although other solid phases (sludge and salt-cake) are also present in the tanks.

As expected based on previous data, uranium is considerably more soluble than plutonium in tank waste supernates. The observed uranium concentrations were typically 1-3 orders of magnitude higher than the plutonium concentrations under the same conditions. For the highly alkaline samples $(2,4$ and 5) in the first 100 days the uranium concentrations were typically in the range of $30-50 \mathrm{mg} / \mathrm{L}$, while the plutonium concentrations were in the range of $1-2 \mathrm{mg} / \mathrm{L}$. At 200-250 days the uranium concentrations for these samples decreased to near $10 \mathrm{mg} / \mathrm{L}$ and the plutonium concentrations decreased slightly to just below $1 \mathrm{mg} / \mathrm{L}$. Sample \#1, which was much more dilute and contained the lowest free hydroxide concentration $(0.168 \mathrm{M})$, generally had the lowest uranium and plutonium concentrations (5-10 $\mathrm{mg} \mathrm{U} / \mathrm{L}$ and 4-7 $\mu \mathrm{g} \mathrm{Pu} / \mathrm{L})$. Plutonium solubility was particularly low for this sample (two orders of magnitude lower than all other samples).

Except for Sample \#3 the uranium and plutonium concentrations generally decreased slowly with time and for most samples a final saturated and stable concentration was never confirmed. Such behavior has been reported previously for highly alkaline solutions. ${ }^{[6]}$ Sample \#1 was an exception since the uranium concentration was stable 
after 50 days. As reported previously for Sample \#1, ${ }^{[3]}$ the as-received solution was supersaturated in uranium and the concentration was observed to decrease rapidly to near the uranium solubility limit after the addition of $\mathrm{U}$ or $\mathrm{Pu}$ spike solutions or pre-formed solids. No other initial solutions were observed to be saturated in uranium or plutonium, although for Sample \#2 the uranium concentration after 200-250 days was only 58\% higher than the original value. For all solutions tested, the final plutonium concentration was at least ten times higher than the initial concentration, indicating that none of the asreceived or as-prepared samples approached plutonium saturation.

X-ray diffraction analysis of the solids isolated from each solubility test revealed that only the uranium solid phase could be observed due to the relatively low masses of plutonium phases present. For Samples 1 through 4 Clarkeite, $\mathrm{NaUO}_{2}(\mathrm{O}) \mathrm{OH} \cdot \mathrm{H}_{2} \mathrm{O}$, was observed as the primary crystalline phase. Clarkeite is the dominant uranium phase observed in SRS tank sludge samples as well. For Sample \#1, Clarkeite was the only phase observed, while other unidentified phases were observed for the remaining samples. For Sample \#5, the primary solid phase observed was sodium diuranate, $\mathrm{NaU}_{2} \mathrm{O}_{7}$. The formation of the diuranate salt is not surprising for this sample given the fact that it contained an extremely high free hydroxide level (almost $9 \mathrm{M}$ ). A sodium uranyl carbonate phase $\left(\mathrm{Na}_{4} \mathrm{UO}_{2}\left(\mathrm{CO}_{3}\right)_{3}\right)$ was also observed for Sample \#5, but we suspect that it may have formed as a result of incomplete sample washing and subsequent reaction between atmospheric carbon dioxide and residual alkaline solution in the samples during transport and storage prior to analysis. Although plutonium crystalline 
phases could not be observed by XRD, all samples contained Pu solids as confirmed by EDS conducted at multiple locations.

Perhaps the most interesting results observed in this study were the long-term solubility results with Sample \#3. This tank sample contained the highest carbonate level, the second lowest free hydroxide level, and the highest carbonate:hydroxide molar ratio (1.4:1) of any of the five original samples tested. In fact this was the only sample of the five original samples that contained a carbonate:hydroxide level greater than one. Uranium and plutonium concentrations comparable to other samples were observed for Sample \#3 during the first 25-50 days of testing. However, extended contact resulted in dramatic increases in the concentrations of both actinides. The uranium concentration increased so much that it was necessary to re-spike the sample with additional uranyl nitrate. The final sub-samples analyzed contained almost $4.5 \mathrm{~g} \mathrm{U} / \mathrm{L}$ (approaching $0.02 \mathrm{M}$ $\mathrm{U}$ ) and $12 \mathrm{mg} \mathrm{Pu} / \mathrm{L}$, which corresponds to $83 \%$ and $24 \%$, respectively, of the uranium and plutonium spike levels for this sample.

Testing could not be continued with these samples since insufficient sample volumes $(<10 \mathrm{~mL})$ remained after 275 to 325 days and final stable actinide concentrations were not obtained. As a result, the reported concentrations may not represent the solubility limits for this sample. Based on these results, we suspect that the initial addition of the acid spike solutions containing actinides to Sample \#3 resulted in the rapid formation of insoluble oxide, hydroxide or mixed hydroxy-carbonate solids which slowly dissolved in the presence of high carbonate concentrations to form highly soluble actinide carbonate 
species. Although Sample \#3 contained the highest carbonate concentration of any sample tested, it also contained the highest sulfate concentration. Sulfate is also known to form strong complexes with actinides ${ }^{[12]}$ and therefore may have contributed in part to the high solubilities of uranium and plutonium in this sample.

In order to gain insight as to the reasons for the extremely high solubilities observed with Sample \#3, chemically-modified samples were prepared with elevated concentrations of carbonate, nitrate, and sulfate. Sample \#1 was used as the base supernate solution for the preparation of chemically-modified samples because it had the lowest free hydroxide concentration and was therefore expected to be impacted the greatest by the addition of other complexing anions. The primary interest was on the influence of carbonate and sulfate on uranium and plutonium solubilities.

An aliquot of Sample \#1 identified as Sample \#1-N was spiked with nitrate to generate a control sample with the same total sodium concentration as those samples spiked with carbonate (1-C) and sulfate (1-S). Each modified sample contained approximately $2 \mathrm{M}$ total sodium and the carbonate and sulfate concentrations were each $0.75 \mathrm{M}$. Solubility tests were conducted with these samples over a period of approximately 150 days. Uranium analysis results revealed that during this period the average $U$ concentrations for carbonate-, nitrate-, and sulfate-spiked samples were 17, 3.2, and $4.9 \mathrm{mg} \mathrm{U} / \mathrm{L}$, respectively. The results indicate that the addition of both the sodium nitrate and sulfate salts resulted in slightly decreased uranium solubility, since the concentration measured for un-spiked Sample \#1 during a comparable time period was 7-8 mg U/L. The addition 
of the carbonate salt resulted in enhanced uranium solubility. Plutonium measurements revealed that during the 150 day contact period the average $\mathrm{Pu}$ concentrations for carbonate-, nitrate- and sulfate-spiked samples were 351,2 , and $17 \mu \mathrm{g} \mathrm{Pu} / \mathrm{L}$. The addition of sodium nitrate salt resulted in decreased plutonium solubility, since the solubility observed for Sample \#1 during a comparable time period was $7 \mu \mathrm{g} / \mathrm{L}$.

We have previously reported that a minimum in plutonium solubility was observed during evaporation studies near $2.5 \mathrm{M} \mathrm{Na}^{+} .^{[4]}$ The addition of both carbonate and sulfate salts resulted in enhanced plutonium solubility, with dramatic increases observed with carbonate (176 times greater solubility than observed for the nitrate control). Presumably, had the solubility tests been continued for a sufficiently long time period (approaching one year) the actinide solubilities would have increased significantly for the carbonate-spiked sample, as observed in the testing with Sample \#3, which also had a high carbonate concentration. Based on these results and literature review, we believe that carbonate complex formation is the likely cause of the dramatic actinide solubility increases observed with Sample \#3, although sulfate may contribute to some extent for plutonium.

Comparison of the results to predictions generated using statistically-based models developed at SRNL, ${ }^{[5]}$ revealed that the models predict the solubility relatively well in some cases (particularly for relatively short time scales) but not in others. The uranium model predicted solubilities very similar to the observed values at 50-100 days for Samples 2, 3 and 5. The plutonium model predicted solubilities similar to the observed 
values at 50-100 days for Samples 1-3 and 5. This was not surprising since these models were based on short term data collected up to a maximum of about 180 days.

\section{CONCLUSIONS}

The solubility behavior of uranium and plutonium were determined for several actual radioactive SRS tank farm and process solutions. The primary solid phase of uranium observed in equilibrium with the tank waste supernate solutions was Clarkeite at hydroxide concentrations $<3.9$ M. For tank waste Sample \#5, which has a much higher hydroxide concentration $(8.7 \mathrm{M})$, the primary solid phase was found to be sodium diuranate.

Results revealed that solubility models developed at SRNL predict the solubility of uranium and plutonium well in some cases at short contact times but not in others. Uranium super-saturation was observed in one tank farm sample (as reported previously ${ }^{[3]}$ ). Extremely high solubility was observed over long time periods for a dissolved salt-cake sample containing high carbonate, high sulfate and relatively low hydroxide. Based on separate studies with carbonate-spiked supernate and literature reviews it is believed that carbonate complex formation leads to the exceptionally high uranium and plutonium solubilities observed with this sample.

The results indicate that super-saturated and high carbonate solutions stored for extended time periods could serve as carrier solutions for uranium and plutonium that could rapidly 
precipitate upon exposure to certain solids or mixing with other process solutions with lower inherent solubilities for these actinides. These characteristics of tank supernate solutions must be taken into consideration when developing waste processing strategies within the SRS tank farm. 


\section{REFERENCES}

1. Clark, D. L., Hobart D. E., Neu, M. P. (1995) Actinide carbonate complexes and their importance in actinide environmental chemistry. Chem. Rev., 95: 25 (and references therein).

2. Allard, B. (1982) Actinides in Perspective; Pergamon Press, Inc.: New York, 1982, pp. 553-580.

3. King, W. D., Wilmarth, W. R., Hobbs, D. T., Edwards, T. B. (2008) Recent studies of uranium and plutonium chemistry in alkaline radioactive waste solutions. J. Alloys and Comp., 458:158.

4. Hobbs, D. T., Karraker, D. G. (1996) Recent results on the solubility of uranium and plutonium in Savannah River Site waste supernate. Nuclear Technology, 114: 318 .

5. Rudisill, T. S., Hobbs, D. T., Edwards, T. B. (2009) Plutonium solubility in simulated Savannah River Site waste solutions. Sep. Sci. Technol., in review.

6. Delegard, C. H. (1987) Solubility of $\mathrm{PuO}_{2} \cdot x \mathrm{H}_{2} \mathrm{O}$ in alkaline Hanford high-level waste solution. Radiochim. Acta, 41: 11.

7. Yamamura, T., Kitamura, A., Fukui, A., Nishikawa, S., Yamamota, T.; Moriyama, H. (1998) Solubility of U(VI) in highly basic solutions. Radiochim. Acta, 83: 139.

8. Clark, D. L., Conradson, S. D., Donohue, R. J., Webster Keogh, D., Morris, D. E., Palmer, P. D., Rogers, R. D., Tait, C. D. (1999) Chemical speciation of the uranyl ion under highly alkaline conditions. Synthesis, structures, and oxo ligand exchange dynamics. Inorg. Chem., 38: 1456. 
9. Wahlgren, U., Moll, H., Grenthe, I., Schimmelpfennig, B., Maron, L., Vallet, V., Gropen, O. (1999) Structure of uranium (VI) in strong alkaline solutions. A combined theoretical and experimental investigation. J. Phys. Chem. A, 103: 8257.

10. Budaventzeva, N. A., Tananaev, I. G., Fedoseev, A. M., Delegard, C. H. (1998) Behavior of plutonium (V) in alkaline media. J. Alloys Comp., 271-273: 813.

11. Guilaumont, R., Adloff, J. P. (1992) Stability of pentavalent plutonium. Radiochim. Acta, 58/59: 45.

12. Katz, J. J., Seaborg, G. T., Morss, L. R. The Chemistry of the Actinide Elements, $2^{\text {nd }}$ Ed., Vol. 1; Chapman and Hall: New York, 1986.

13. Zhou, P., Gu, B. (2005) Extraction of oxidized and reduced forms of uranium from contaminated soils: Effects of carbonate concentration and pH", Environ. Sci. Technol., 39: 4435.

14. Giammar, D. E., Hering, J. E. (2004) Influence of dissolved sodium and cesium on uranyl oxide hydrate solubility. Environ, Sci. Technol., 38: 171.

15. Haschke, J. M., Allen, T. H. (2002) Equilibrium and thermodynamic properties of the $\mathrm{PuO}_{2+\mathrm{x}}$ solid solution. J. Alloys Comp., 336: 124 .

16. Cinneide, S. O., Scanlan, J. P.; Hynes, M. J. (1975) Equilbria in uranyl carbonate systems - I, The overall stability constant of $\mathrm{UO}_{2}\left(\mathrm{CO}_{3}\right)_{3}{ }^{4-}$. J. Inorg. Nucl. Chem., 37: 1013.

17. Scanlan, J. P. (1977) Equilbria in uranyl carbonate systems - II, The overall stability constant of $\mathrm{UO}_{2}\left(\mathrm{CO}_{3}\right)_{2}{ }^{2-}$ and the third formation constant of $\mathrm{UO}_{2}\left(\mathrm{CO}_{3}\right)_{3}{ }^{4}$. J. Inorg. Nucl. Chem., 39: 635. 
18. Allen, P. G., Bucher, J. J., Clark, D. L., Edelstein, N. M., Ekberg, S. A., Gohdes, J. W., Hudson, E. A., Kaltsoyannis, N., Lukens, W. W., Neu, M. P., Palmer, P. D., Reich, T., Shuh, D. K., Tait, C. D., Zwick, B. D. (1995) Multinuclear NMR, Raman, EXAFS, and X-ray Diffraction studies of uranyl carbonate complexes in near-neutral aqueous $\quad$ solution. $\quad$-ray structure of $\left[\mathrm{C}\left(\mathrm{NH}_{2}\right)_{3}\right]_{6}\left[\left(\mathrm{UO}_{2}\right)_{3}\left(\mathrm{CO}_{3}\right)_{6}\right] \cdot 6.5 \mathrm{H}_{2} \mathrm{O}$. Inorg. Chem., 34: 4797. 
Table 1. Initial Concentrations (Molarity) and Densities (g/mL) of SRS Tank Waste Supernate Solutions Tested.

\begin{tabular}{|c|c|c|c|c|c|}
\hline Sample ID & $\mathbf{1}$ & $\mathbf{2}$ & $\mathbf{3}$ & $\mathbf{4}$ & $\mathbf{5}$ \\
\hline sodium & 0.494 & 6.02 & 6.29 & 6.92 & 11.9 \\
\hline potassium & $1.40 \mathrm{E}-02$ & $4.12 \mathrm{E}-02$ & $<1.34 \mathrm{E}-02$ & $4.13 \mathrm{E}-02$ & $1.72 \mathrm{E}-01$ \\
\hline aluminum & $2.42 \mathrm{E}-03$ & $2.33 \mathrm{E}-01$ & $2.00 \mathrm{E}-02$ & $1.77 \mathrm{E}-01$ & $6.64 \mathrm{E}-01$ \\
\hline nitrate & $4.63 \mathrm{E}-02$ & 1.25 & 3.26 & 2.05 & 2.08 \\
\hline nitrite & $1.63 \mathrm{E}-01$ & 0.799 & $6.73 \mathrm{E}-02$ & 1.65 & 1.82 \\
\hline hydroxide* & $1.68 \mathrm{E}-01$ & 3.87 & 0.530 & 1.75 & 8.72 \\
\hline carbonate & $4.40 \mathrm{E}-02$ & $<0.297$ & 0.723 & 0.616 & $<0.317$ \\
\hline phosphate & $<1.60 \mathrm{E}-03$ & $3.72 \mathrm{E}-03$ & $<1.60 \mathrm{E}-03$ & $1.28 \mathrm{E}-02$ & $2.00 \mathrm{E}-02$ \\
\hline sulfate & $<7.91 \mathrm{E}-04$ & $1.17 \mathrm{E}-02$ & 0.598 & 0.293 & $8.09 \mathrm{E}-03$ \\
\hline fluoride & $<1.60 \mathrm{E}-03$ & $7.69 \mathrm{E}-03$ & $<1.60 \mathrm{E}-02$ & $<1.59 \mathrm{E}-03$ & $<1.67 \mathrm{E}-03$ \\
\hline formate & $5.06 \mathrm{E}-03$ & $7.17 \mathrm{E}-03$ & $<1.38 \mathrm{E}-02$ & $<3.38 \mathrm{E}-03$ & $<3.53 \mathrm{E}-03$ \\
\hline oxalate & $<1.37 \mathrm{E}-03$ & $1.73 \mathrm{E}-03$ & $<1.37 \mathrm{E}-02$ & $4.49 \mathrm{E}-03$ & $<1.43 \mathrm{E}-03$ \\
\hline Total U & $7.95 \mathrm{E}-05$ & $2.70 \mathrm{E}-05$ & $6.80 \mathrm{E}-06$ & $4.98 \mathrm{E}-06$ & $5.10 \mathrm{E}-06$ \\
\hline Total Pu & $1.29 \mathrm{E}-09$ & $1.05 \mathrm{E}-08$ & $1.62 \mathrm{E}-08$ & $3.54 \mathrm{E}-09$ & $1.21 \mathrm{E}-08$ \\
\hline Density (g/mL) & 1.02 & 1.27 & 1.31 & 1.32 & 1.47 \\
\hline
\end{tabular}

*hydroxide measured as free or uncomplexed

Table 2. Descriptions and Histories of SRS Tank Waste Supernate Solutions Tested.

\begin{tabular}{|c|c|}
\hline Sample ID & Description and History \\
\hline 1 & dilute DWPF recycle stream \\
\hline 2 & evaporator feed \\
\hline 3 & recently dissolved salt cake \\
\hline 4 & dissolved salt with high sulfate, cladding waste, dormant for decades \\
\hline 5 & evaporator concentrate \\
\hline
\end{tabular}

*DWPF $=$ Defense Waste Processing Facility

Table 3. Concentrations (Molarity) and Densities $(\mathrm{g} / \mathrm{mL})$ of Chemically-Modified Sample \#1 Solutions Tested.

\begin{tabular}{|c|c|c|c|}
\hline Modifed Sample ID & $\mathbf{1 - C}$ & $\mathbf{1 - N}$ & $\mathbf{1 - S}$ \\
\hline sodium & $2.00^{*}$ & $1.99^{*}$ & $1.99^{*}$ \\
\hline carbonate & $0.751^{*}$ & 0.044 & 0.044 \\
\hline nitrate & $5.00 \mathrm{E}-02$ & $1.597^{*}$ & $4.70 \mathrm{E}-02$ \\
\hline sulfate & $<5.20 \mathrm{E}-4$ & $<5.20 \mathrm{E}-4$ & $0.750^{*}$ \\
\hline Density (g/mL) & 1.08 & 1.09 & 1.10 \\
\hline
\end{tabular}

$*$ indicates altered concentrations resulting from added solids 
Table 4. U and Pu Concentrations in Original and Spiked Tank Supernate Samples along with Predicted and Observed (over-saturation only) Solubility Data versus Time.

\begin{tabular}{|l|c|c|c|c|c|}
\hline \multicolumn{7}{|c|}{ Sample } & $\mathbf{2}$ & $\mathbf{2}$ & $\mathbf{4}$ & $\mathbf{5}$ \\
\hline Uranium (mg/L) & \multicolumn{5}{|c|}{} \\
\hline Initial & 19 & 6.4 & 1.5 & 1.2 & 1.2 \\
\hline Spike Level & 2400 & 2400 & $5400^{*}$ & 1200 & 3600 \\
\hline Model Prediction & 51 & 30 & 32 & 11 & 41 \\
\hline 25-50 Days & 8.3 & 29.5 & 26.1 & 53.5 & 41.5 \\
\hline 50-100 Days & 6.8 & 35.4 & 1323 & 28.2 & 38.8 \\
\hline 200-250 Days & 6.9 & 10.1 & 1391 & 5.9 & 14.1 \\
\hline 275-325 Days & --- & --- & 4458 & --- & --- \\
\hline Plutonium (mg/L) & \multicolumn{5}{|l|}{} \\
\hline Initial & $3.8 \mathrm{E}-4$ & $3.0 \mathrm{E}-3$ & $4.1 \mathrm{E}-3$ & $1.1 \mathrm{E}-3$ & $3.6 \mathrm{E}-3$ \\
\hline Spike Level & 28 & 50 & 50 & 50 & 25 \\
\hline Model Prediction & $1.3 \mathrm{E}-2$ & 2.0 & 0.82 & 0.10 & 0.47 \\
\hline 25-50 Days & $6.9 \mathrm{E}-03$ & 1.2 & 1.8 & 1.0 & 2.3 \\
\hline 50-100 Days & $7.0 \mathrm{E}-03$ & 1.0 & 0.94 & 1.2 & 1.3 \\
\hline 200-250 Days & $3.7 \mathrm{E}-03$ & 0.32 & 4.0 & 0.55 & 0.72 \\
\hline 275-325 Days & --- & --- & 12 & --- & --- \\
\hline
\end{tabular}

*initial uranium spike level: $2400 \mathrm{mg} / \mathrm{L}$, additional $3000 \mathrm{mg} / \mathrm{L}$ spike after 250 days 
Figure 1. Measured and Predicted Uranium Solubilities for Tank Waste Supernates at $25^{\circ} \mathrm{C}$ (over-saturation data only).

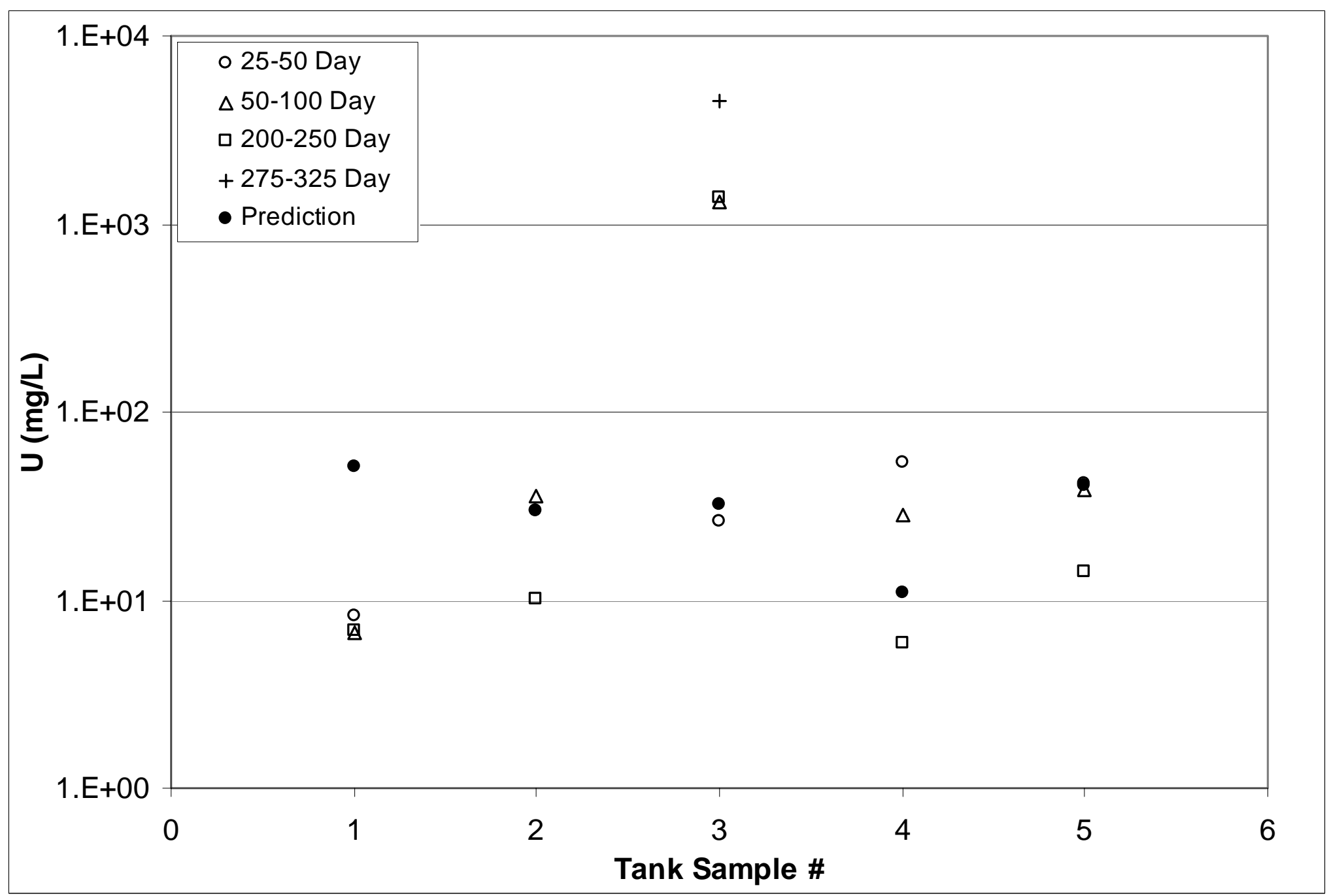


Figure 2. Measured and Predicted Plutonium Solubilities for Tank Waste Supernates at $25^{\circ} \mathrm{C}$ (over-saturation data only).

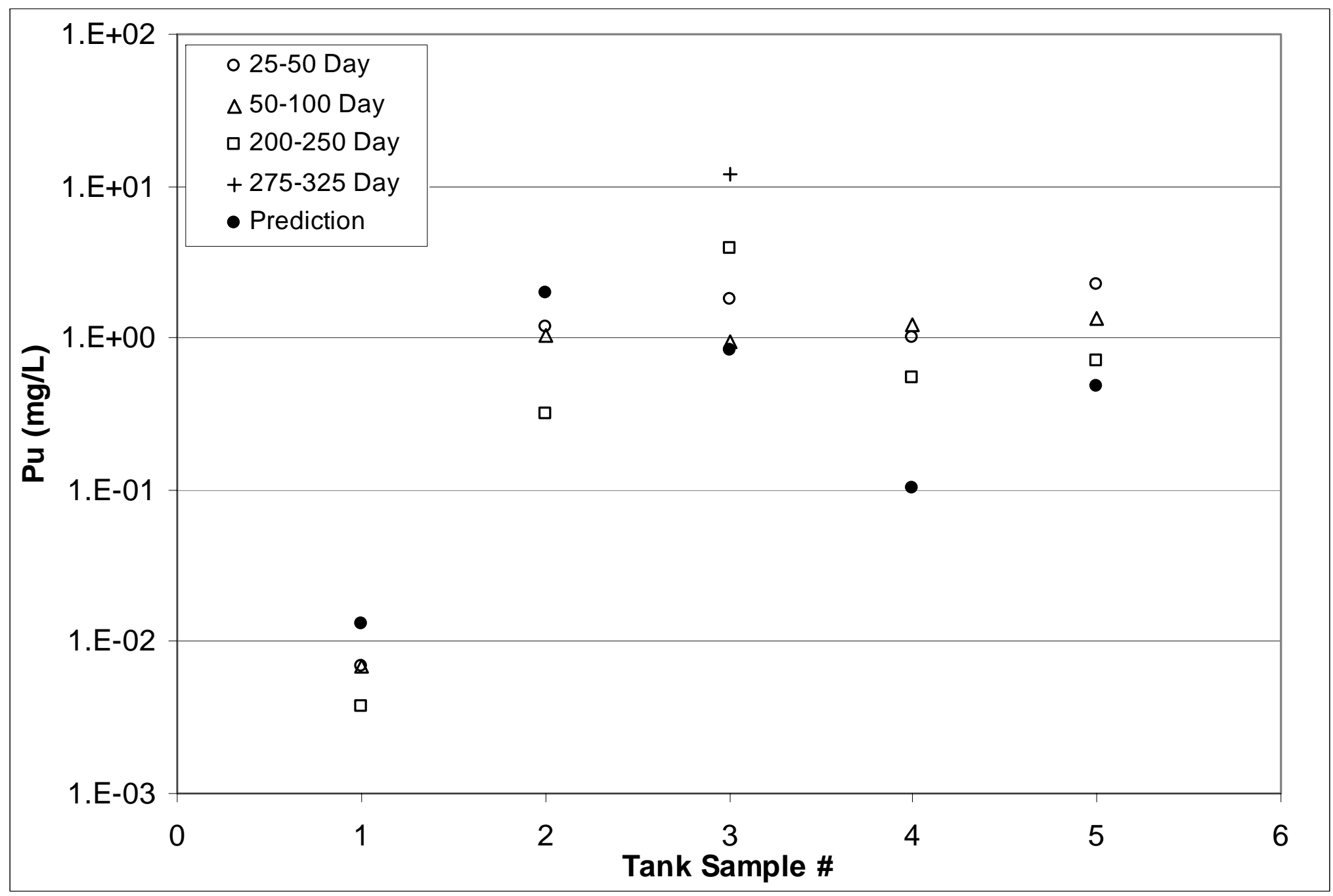


SRNL-STI-2010-00140

\section{Figure Captions}

Figure 1. Measured and Predicted Uranium Solubilities for Tank Waste Supernates at 25 ${ }^{\circ} \mathrm{C}$ (over-saturation data only).

Figure 2. Measured and Predicted Plutonium Solubilities for Tank Waste Supernates at $25{ }^{\circ} \mathrm{C}$ (over-saturation data only). 